\title{
Infection Behavior of Venturia nashicola, the Cause of Scab on Asian Pears
}

\author{
P. Park, H. Ishii, Y. Adachi, S. Kanematsu, H. Ieki, and S. Umemoto
}

First author: The Graduate School of Science and Technology, Kobe University, Hyogo 657-8501, Japan; second author: National Institute of Agro-Environmental Sciences, Tsukuba, Ibaraki 305-8604, Japan; third, fourth, and fifth authors: National Institute of Fruit Tree Science, Tsukuba, Ibaraki 305-8605, Japan; and sixth author: Chiba Experimental Agriculture Station, Chiba 266-000, Japan. Current address of S. Kanematsu: Apple Research Center, National Institute of Fruit Tree Science, Morioka, Iwate 020-0123, Japan. Current address of H. Ieki: Parsimmon and Grape Research Center, National Institute of Fruit Tree Science, Akitsu, Hiroshima 729-2494, Japan. Accepted for publication 7 August 2000.

\begin{abstract}
Park, P., Ishii, H., Adachi, Y., Kanematsu, S., Ieki, H., and Umemoto, S. 2000. Infection behavior of Venturia nashicola, the cause of scab on Asian pears. Phytopathology 90:1209-1216.

The infection of Japanese pear by Venturia nashicola, the cause of scab on Asian pears (Japanese pear, Pyrus pylifolia var. culta; Chinese pear, P. ussuriensis), was examined using light and electron microscopy to determine the mechanism of resistance in pears. Early stages of infection were similar on the susceptible cv. Kosui, the resistant cv. Kinchaku, and the nonhost European pear (P. communis) cv. Flemish Beauty. $V$. nashicola penetrated only the cuticle layer on pear leaves and formed

subcuticular hyphae on all three cultivars. Hyphae were localized in the pectin layer of pear leaves and never penetrated into the cytoplasm of epidermal cells. This restriction of fungal growth suggested that pectinases released by infection hyphae or subcuticular hyphae may be important in infection. Subcuticular hyphae were modified ultrastructurally in the pectin layer of resistant pear cultivars accompanied by fungal cell death. In contrast, fungal cells appeared intact in susceptible pear cultivars, suggesting the existence of resistance mechanisms.

Additional keywords: disease resistance, electron microscopy, pear scab, pectin.
\end{abstract}

Scab, caused by Venturia nashicola Tanaka et Yamamoto (10,23), is one of the major diseases of Asian pears such as Japanese pear (Pyrus pyrifolia Nakai var. culta Nakai) and Chinese pear $(P$. ussuriensis Maxim.). All commercial cultivars of Japanese pear are susceptible to this pathogen; consequently, there is a high dependence of growers on fungicides to control the disease. However, the noncommercial cv. Kinchaku was found to be highly resistant to both $V$. nashicola and $V$. pirina Aderhold, the cause of scab on European pear ( $P$. communis L.) $(8,9)$. In addition, European pear cultivars are nonhost of $V$. nashicola $(8,10,23)$.

Although scab of Japanese pear is a serious economic problem, there is not much known about the infection process of $V$. nashicola. Müller and Ishii (16) recently reported the histochemical detection of esterase activity by $V$. nashicola and discussed its possible involvement in the pathogenesis of scab. An earlier work (26) suggested that $V$. nashicola penetrated cuticle layers of susceptible pear leaves, but the infection through stomata was rarely observed. However it remains unclear what cellular events happen in fungal and infected plant cells at the early stages of scab infection process.

With V. inaequalis (Cooke) G. Wint., the cause of apple scab, the germ tube developed from a conidium contacts the cuticle, an appressorium forms, and a mucilaginous substance (slime) is secreted and fixes appressoria firmly to the cuticle (13). The germ tube usually entered the host directly over a juncture of two epidermal cells or where several cells met (2). Cuticular penetration of the fungus was detected in leaves of scab-resistant cultivars as often as in those of susceptible ones, suggesting that the cuticular

Corresponding author: H. Ishii; E-mail address: hideo@niaes.affrc.go.jp

Publication no. P-2000-0911-02R

(C) 2000 The American Phytopathological Society membrane does not represent an effective performed physical barrier for the pathogen (25). Upon penetration of the cuticle, the fungus usually grew in a platelike manner, a subcuticular stroma formed, and conidiogenesis was initiated.

In this study, we attempted to examine the early and late stages of the infection behavior of $V$. nashicola on host and nonhost pear leaves under a light and an electron microscope to help understanding the resistance mechanism.

\section{MATERIALS AND METHODS}

Plants. Japanese pear cvs. Kosui and Kinchaku and European pear cv. Flemish Beauty were used. These cultivars show susceptibility, resistance, and nonhost resistance to V. nashicola, respectively (8). Scions of pear were sampled during the dormant period, cut grafted to the potted $(24 \mathrm{~cm}$ in diameter) seedling stocks of $P$. pyrifolia Nakai (Yamanashi) in spring, and then maintained in a greenhouse. Two-year-old grafted pear plants were used for inoculation.

Fungal inoculation. Conidia of $V$. nashicola race 1 were harvested from naturally scab-infected Japanese pear grown in Tsukuba, Ibaraki, washed with distilled water by centrifugation, and suspended in $0.1 \%$ sucrose solution (8). The conidial concentration was adjusted to $\approx 5 \times 10^{5}$ conidia/ml. Drops $(\approx 20 \mu \mathrm{l})$ of the conidial suspension were placed on the upper epidermis of young leaves of potted plants (two replicates) of each of the three pear cultivars. After air drying, the inoculated plants were placed in a moist chamber at $20^{\circ} \mathrm{C}$ for $48 \mathrm{~h}$, transferred to a phytotron, and maintained at $25^{\circ} \mathrm{C}$. The inoculated leaves were then detached from the plants $0.5,1,2,3,5$, and 7 days after inoculation and used as specimens for light and electron microscopy. The inoculation test for light microscopy was carried out twice.

Light microscopy. Portions of leaves inoculated with conidia were excised and cleared in a 96:4 mixture of ethanol and acetic 
acid at $65^{\circ} \mathrm{C}$ for $1 \mathrm{~h}$. Fungal structures were stained with lactophenol cotton blue solution according to methods previously reported (16). Stained samples were dipped in lactic acid and monitored for the early development stages of the fungus using a Nikon Biophot microscope (Nikon, Tokyo) at magnification $\times 400$. One hundred conidia were selected arbitrarily from two to three droplets of suspension and the formation of germ tubes, appressoria, penetration pores, and subcuticular hyphae was determined for each treatment. Mean values and standard errors were calculated.

Electron microscopy. Portions of leaves inoculated with conidia were trimmed into small pieces $(2 \times 2 \mathrm{~mm})$ with a razor blade. Leaf pieces were prefixed with $3 \%$ glutaraldehyde $(1 / 15 \mathrm{M}$ phosphate buffer, $\mathrm{pH} 7.4)$ at room temperature $\left(\approx 25^{\circ} \mathrm{C}\right)$ overnight and postfixed with the $1 \%$ buffered osmium tetroxide at room temperature for $2 \mathrm{~h}$. The fixed leaves were dehydrated with ethanol and embedded with Quetol-Araldite resin (Nisshin EM, Tokyo) or Spurr resin as reported previously (19). Ultrathin sections were cut from the resin blocks by using a glass and diamond knife. The sections were stained with $4 \%$ uranyl acetate for 30 min and counterstained with either Reynolds's lead solution (20) or Sato's lead solution (21) for $10 \mathrm{~min}$. Sections were observed with an electron microscope 1200EX of JEOL (Tokyo).

Method for observing epidermal cell-microbe encounter sites. Fifty $3-\mu \mathrm{m}$ thick semithin sections from one resin block were cut with a Histo diamond knife (DIATOME, Bienne, Switzerland) at one time and floated on distilled water in the knife boat. The semithin sections were picked up with a 5-mm-diameter platinum wire loop from the boat. The captured water layers con- taining semithin sections in the loop were inverted on water droplets, which had been placed previously on glass slides. Water droplets were then heated on a hot plate at approx. $75^{\circ} \mathrm{C}$ and dried until the sections stretched and adhered to the glass slides. The sections on glass slides were stained with $0.6 \%$ toluidine blue in $1 \%$ sodium borate for 5 to $10 \mathrm{~s}$ on the hot plate and then briefly rinsed with distilled water. After drying, all stained sections were observed under a light microscope to identify the presence of structures such as conidia, germ tubes, and appressoria on the epidermis. Only the semithin sections with the target structures were used as electron microscopic specimens.

Newly prepared Quetol-Araldite resin was poured into silicon BEEM capsules. The capsules were placed upside down on the semithin sections on the glass slides. The resin in capsules was polymerized at $60^{\circ} \mathrm{C}$ for 3 days in an oven. After polymerization, the backsides of glass slides just beneath the bottom of capsules were heated with a gas lighter for 3 to $5 \mathrm{~s}$. The capsules were then quickly pushed horizontally with a thumb and peeled off the glass slides. The semithin sections were located on the bottom of polymerized resins of the capsules. The silicon covers of the capsules were removed and the resin blocks were placed on glass slides with the flat block bottoms oriented so they could be observed with a light microscope. After identifying the location of the target structure under the microscope, blocks were filled with a block-trimming holder and trimmed with a stainless steel blade (S35 type of microtome blade, FEATHER, Osaka, Japan) under a stereomicroscope. The semithin sections were cut with a porter Blum MT-1 microtome using a diamond knife. After correcting
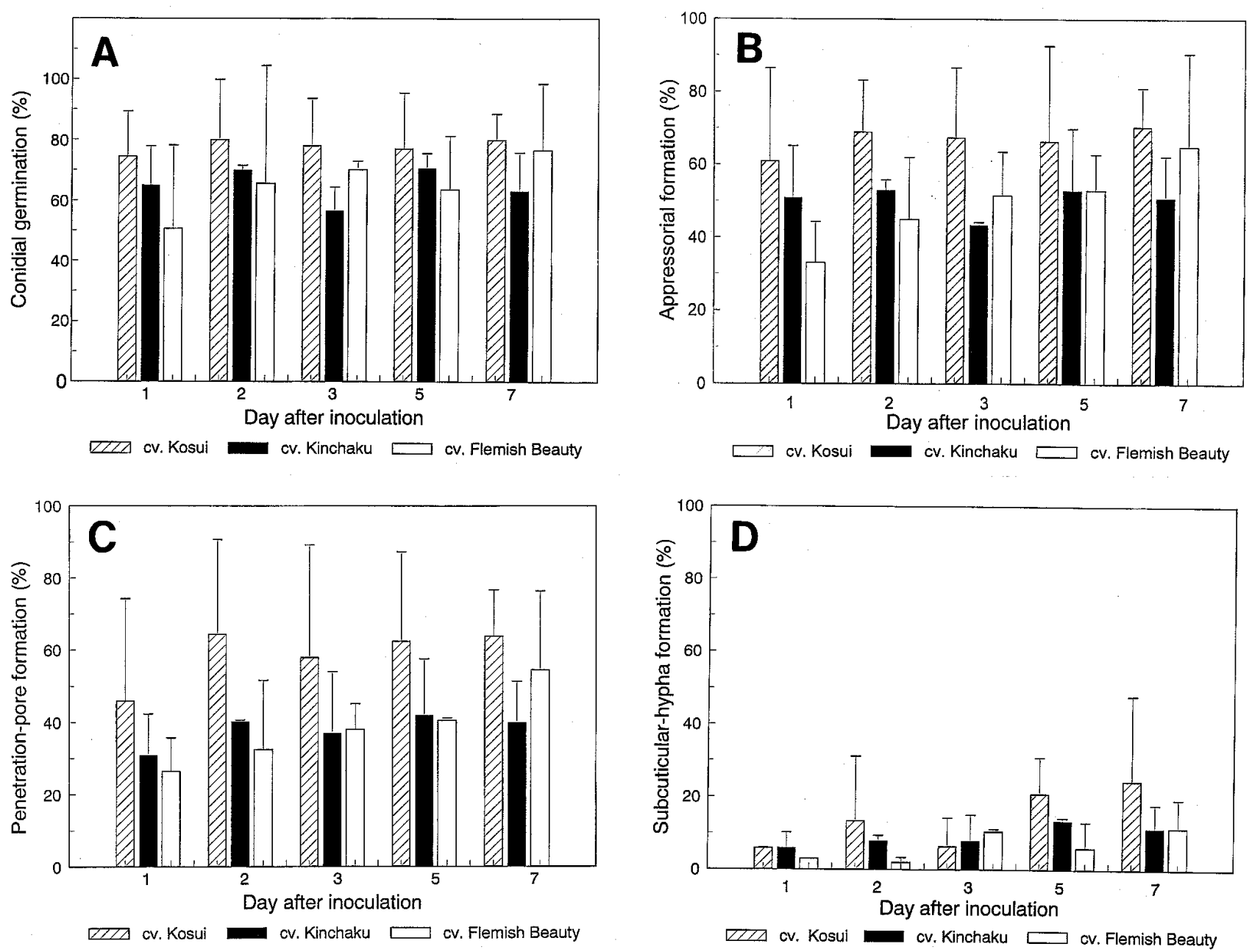

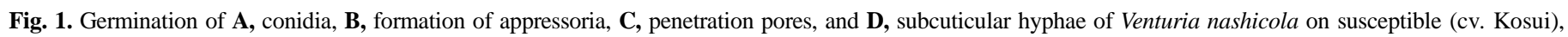
resistant (cv. Kinchaku), and nonhost (cv. Flemish Beauty) pear leaves 1, 2, 3, 5, and 7 days after inoculation. 
the tilt of the blocks, 20 to 30 ultrathin sections with a thickness of $80 \mathrm{~nm}$ were prepared from semithin specimens and mounted in type T 200 of the thin bar grids with high open area (Nisshin EM, Tokyo).

\section{RESULTS}

Infection process of $\boldsymbol{V}$. nashicola on susceptible, resistant, and nonhost pear leaves. Regardless of the pear cultivar, germination of $V$. nashicola conidia and formation of appressoria after germ tube elongation were often observed on leaves $24 \mathrm{~h}$ after inoculation, after which little additional conidial germination and appressorial formation occurred (Fig. 1A and B). Penetration pores also were observed in the appressoria, which formed $24 \mathrm{~h}$ after inoculation, on both susceptible and resistant pear leaves (Fig. 1C). Subcuticular hyphae were observed in a low frequency $24 \mathrm{~h}$ after inoculation and increased with the incubation time (Fig. 1D).

Ultrastructure of upper epidermis in Japanese and European pear leaves. The upper epidermal cells of Japanese pear leaves contained centrally located large vacuoles with amorphous materials and a small volume of peripheral cytoplasm consisting of nuclei with nucleoli, plastids with starch grains, mitochondria, rough endoplasmic reticulum (RER), Golgi apparatus, microbodies, ribosomes, microtubules, and multivesicular bodies. Plasmodesmata were often observed in the lateral cell walls between epidermal cells. The outermost layers of epidermal cells

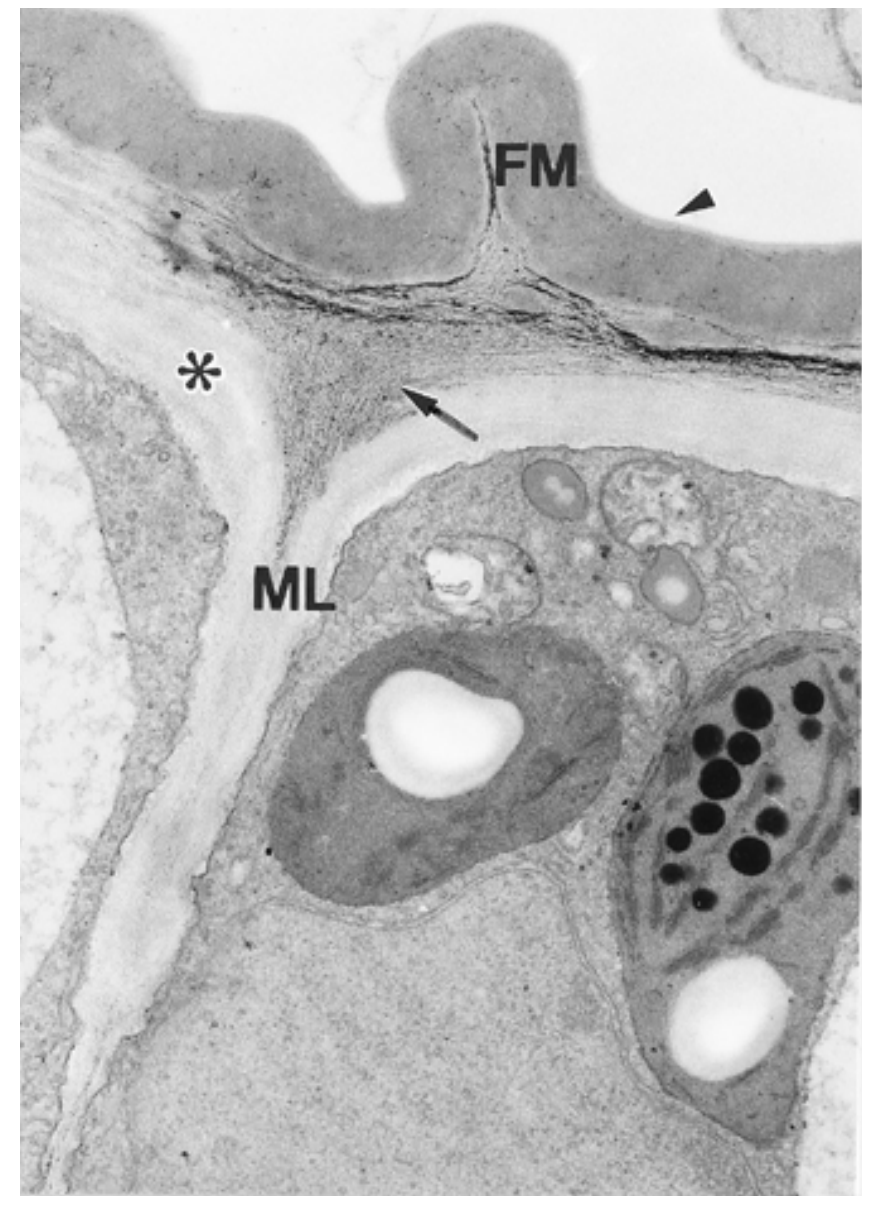

Fig. 2. Upper epidermal cells of susceptible Japanese pear (cv. Kosui) leaf showing the outermost cuticle layers (arrowhead), electron-dense pectincontaining cell walls (pectin layers, arrow), and electron-lucent cellulosecontaining cell walls (cellulose layers, asterisk). The densely stained fibrilar materials (FM) of pectin layers appear to be embedded with cuticle layers. Pectin layers are continuous with middle lamellae (ML) of epidermal cells. Magnification $\times 17,000$. were consistent with the cuticles (Fig. 2, arrowhead), which showed the moderate electron density. Two different layers of cell walls were identified beneath the cuticles: the first was the electron-dense pectin-containing cell wall (pectin layer, Fig. 2, arrow) and the second was the electron-lucent cellulosecontaining cell wall (cellulose layer, Fig. 2, asterisk). Pectin layers were sandwiched between the cuticle and the cellulose layers. Many cuticular ridges formed by the outfolding of cuticles. The cuticle contained network structures consisting of electron-dense fibrilar materials (Fig. 2), which were part of the pectin layers. Pectin layers were densely stained with Sato's lead solution but less densely stained with Reynolds's lead solution. Pectin substances were abundant in the junctures of upper epidermal cells and appeared as the triangular-shaped regions in the cross sections of leaves (Fig. 2). Pectin substances were also continuous with the middle lamellae of epidermal cells. Epidermal cells of European pear leaves were similar in ultrastructure to those of Japanese pear described above.

Infection behavior of $V$. nashicola on susceptible pear leaves. The majority of the conidia of $V$. nashicola formed a single germ tube (which was sometimes branched) on the surface of pear leaves $12 \mathrm{~h}$ after inoculation. The cells of germlings were

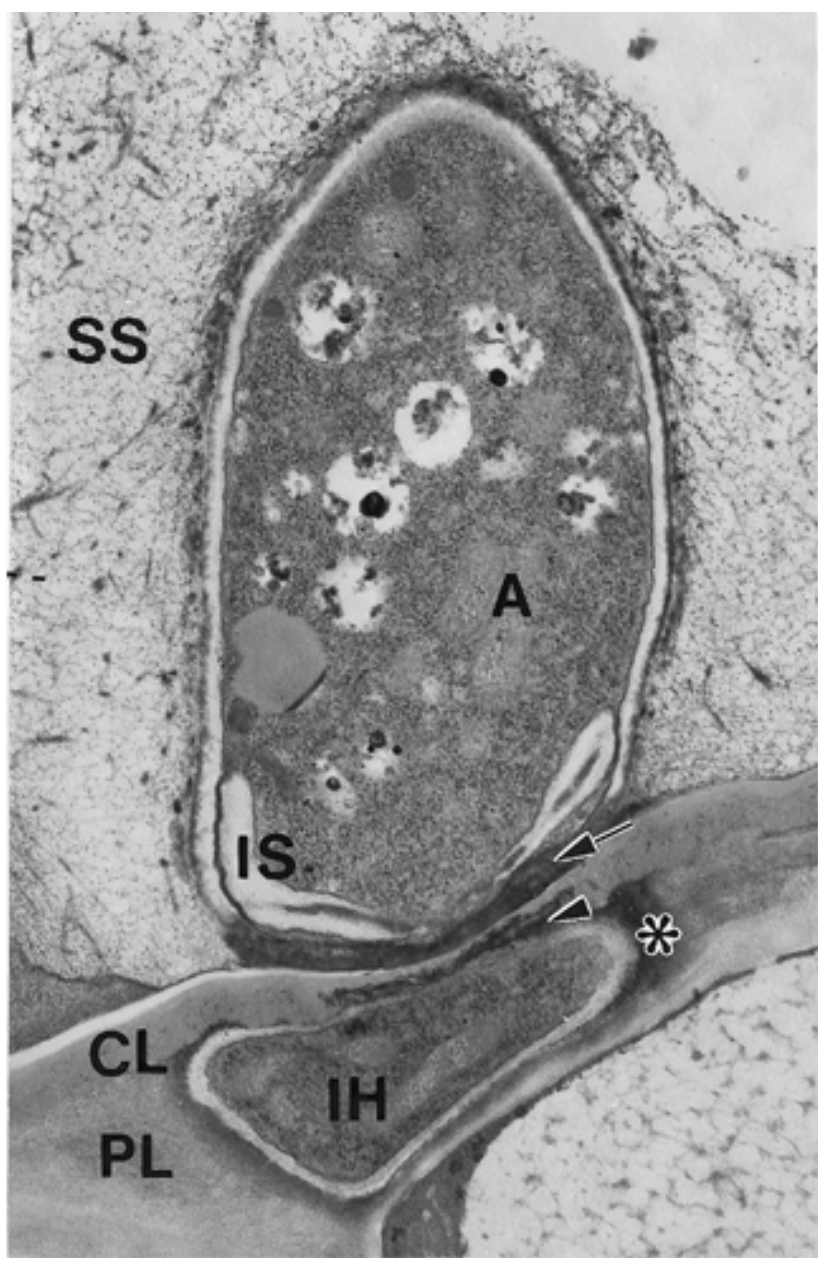

Fig. 3. Appressorium (A) of Venturia nashicola on an epidermal cell of a susceptible Japanese pear (cv. Kosui) leaf $12 \mathrm{~h}$ after inoculation. Infection hypha $(\mathrm{IH})$ has emerged from the appressorium, which is covered with slime substances (SS) consisting of fibrilar and granular components. Appressorium contained a cup-shaped, open-ended structure called an infection sac (IS). Hypha has penetrated cuticle layers (CL) and is located in the pectin layer (PL). Three types of staining materials were found in epidermismicrobe encounter sites: the first (arrow) was located in spaces between the appressoria and cuticle layers, the second (arrowhead) in the cuticle layers, and the third (asterisk) near the pectin layers in contact with the infection hyphae. Magnification $\times 21,000$. 
separated from each other by single-pored septa. Woronin bodies were found in the vicinity of septal pores. The germ tubes consisted of one to several cells. The terminal cells of germ tubes appeared swollen and appressoria were differentiated from the cells. The appressorial cytoplasm contained nuclei with marked nucleoli, mitochondria, vacuoles with electron-dense materials, lipid droplets, RER, and a large volume of free ribosomes. However, no concentric body (5) was found in the cytoplasm of conidia, germ tubes, and appressoria.

Both germ tubes and appressoria were coated with slime consisting of fibrilar and fine granular components (Fig. 3). Appressoria usually contained a cup-shaped, open-ended structure specialized for host cell wall penetration, which has been named an infection sac $(4,14)$ or an appressorial cone $(15)$. Two infection sacs were rarely observed in the appressorial cytoplasm. The sacs were visualized as a single-layered wall and opened into the bottom center of appressoria. No intracellular junctional structures providing a ladder-like appearance described in the literature (3) were found in the sacs. The overall diameter of the sacs in the sections was 1 to $3 \mu \mathrm{m}$. The diameter of opened pores of sacs was similar to that of the penetration pores of appressoria observed in the light microscope. The appressoria had two different cell wall layers: the outer, electron-dense layers and the inner, electronlucent ones. The outer layers were usually connected with the fibrilar components of slime (Fig. 3), whereas the inner ones appeared to be continuous with the walls of infection sacs (Fig. 4). The inner and outer layers of appressoria tapered at the bottom of appressoria (Fig. 3). Subjacent to the infection sacs, the host cuticle appeared thinner (Fig. 3). Infection pegs emerged from the sacs and then penetrated the breached cuticles $12 \mathrm{~h}$ after inoculation.

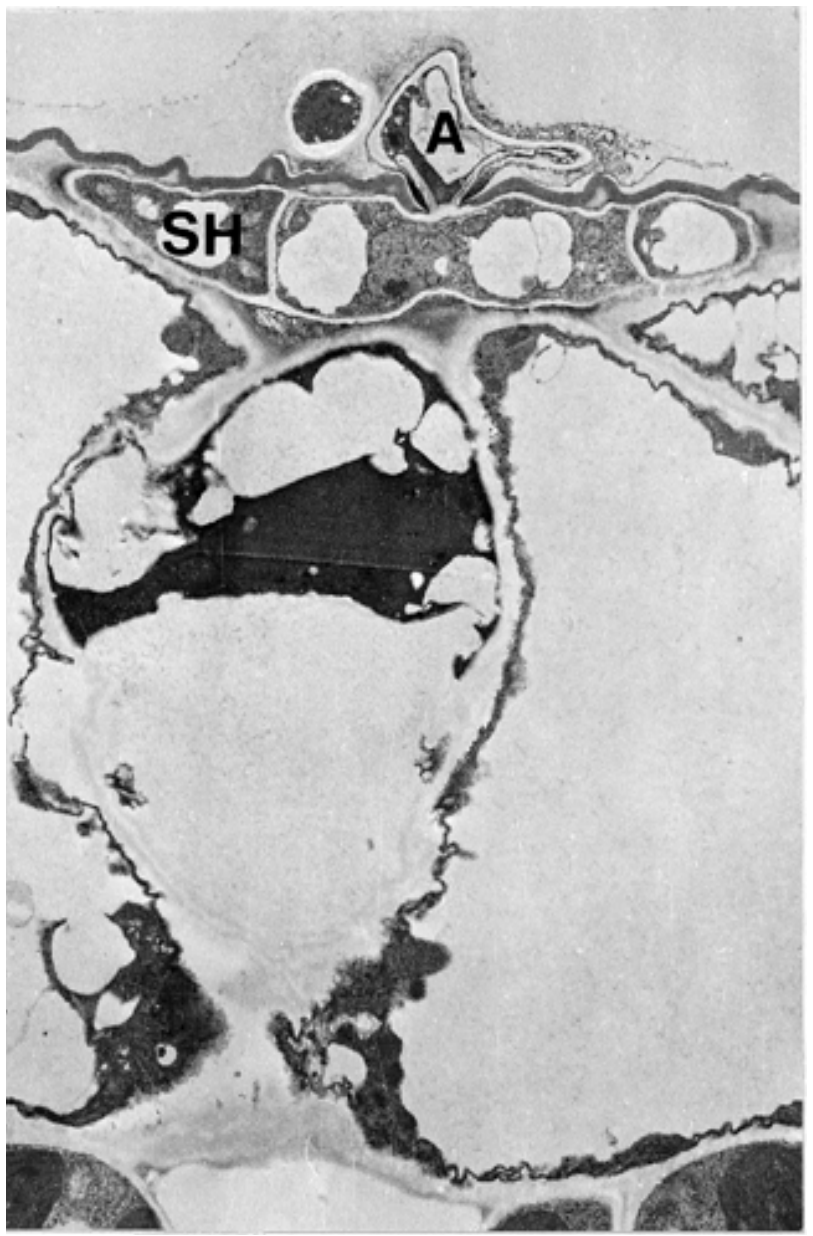

Fig. 4. Horizontal development of subcuticular hyphae of Venturia nashicola emerging from an appressorium (A) alongside the pectin layers 2 days after inoculation. Magnification $\times 5,300$.
Three similar types of densely stained materials were found in the sites where appressoria and host epidermis interacted. Although these materials resembled one another in their ultrastructural appearance, they were located in different tissues. The first were the densely stained materials with white stripes, found in the cuticle layers, which were in contact with the infection pegs (Fig. 3 , arrowhead). The second were found in the restricted spaces between the tapered inner cell walls of appressoria and the cuticle layers (Fig. 3, arrows). The materials were apparently localized on the surfaces of the cuticles. Infection hyphae were usually surrounded by the third type of densely stained materials in the pectin layers (Fig. 3, asterisk). Densely stained materials were not observed in cellulose layers in the vicinity of infection hyphae.

The cellular organelles and components of conidia, germ tubes, and appressoria were transferred to subcuticular hyphae as the infection progressed. As a result, the conidia, germ tubes, and appressoria were often devoid of cytoplasm. After the penetration through the cuticles, subcuticular hyphae developed horizontally from infection sites along the pectin layers between the cuticles and cellulose layers (Fig. 4). Hyphae were not observed penetrating into the cytoplasm of epidermal cells 7 days after inoculation.

Infection behavior of $\boldsymbol{V}$. nashicola on the leaves of resistant Japanese pear and nonhost European pear and cell wall modification. The infection behavior of $V$. nashicola on the leaves of resistant Japanese pear and nonhost European pear cultivars was similar to that on susceptible Japanese pear leaves during the early stages of infection. Conidia produced germ tubes frequently and the germ tubes usually formed appressoria. Germ tubes and appressoria were coated with the fiblilar materials of slime $12 \mathrm{~h}$ after inoculation. The appressorium usually involved a single infection

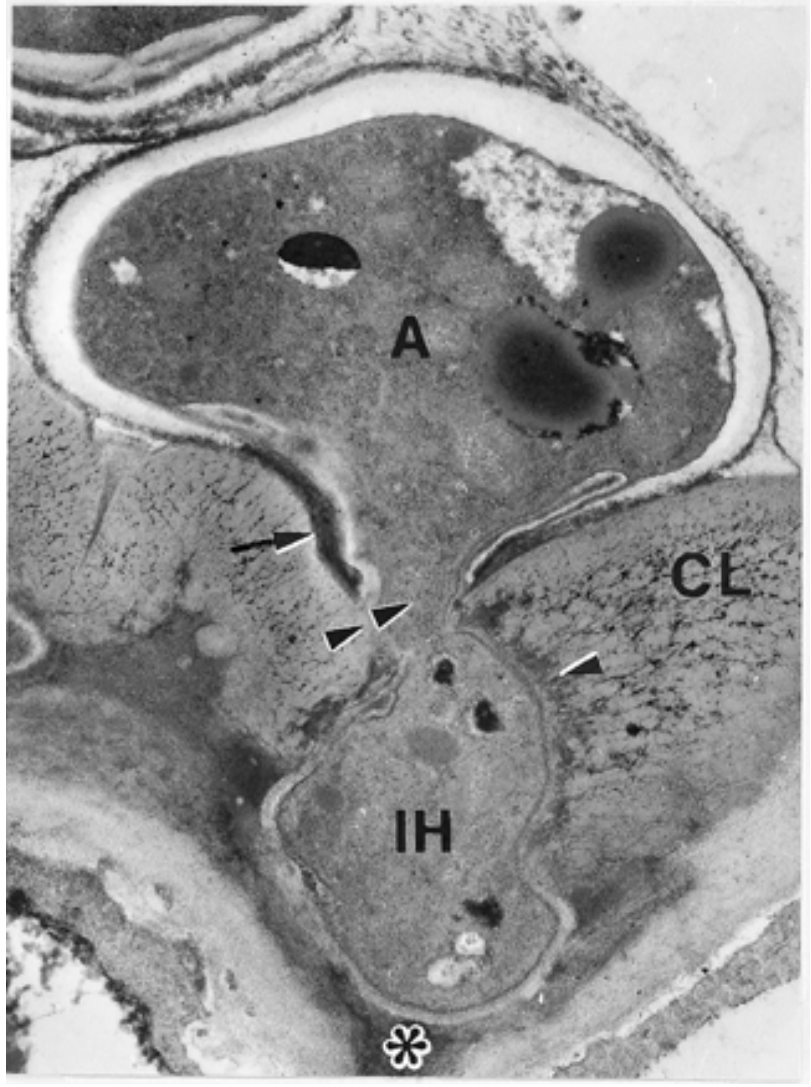

Fig. 5. Infection peg (double arrowheads) emerged from an appressorium (A) penetrating the cuticle layer (CL) of resistant Japanese pear (cv. Kinchaku) leaf resulting in the formation of infection hypha (IH) 1 day after inoculation. A network of fibrilar pectin materials has been formed in the cuticle layers. The arrow indicates densely stained materials between the appressorium and cuticle layers, the arrowhead indicates stained materials in cuticle layers, and the asterisk indicates those in pectin layers as indicated in Figure 3. Magnification $\times 16,500$. 


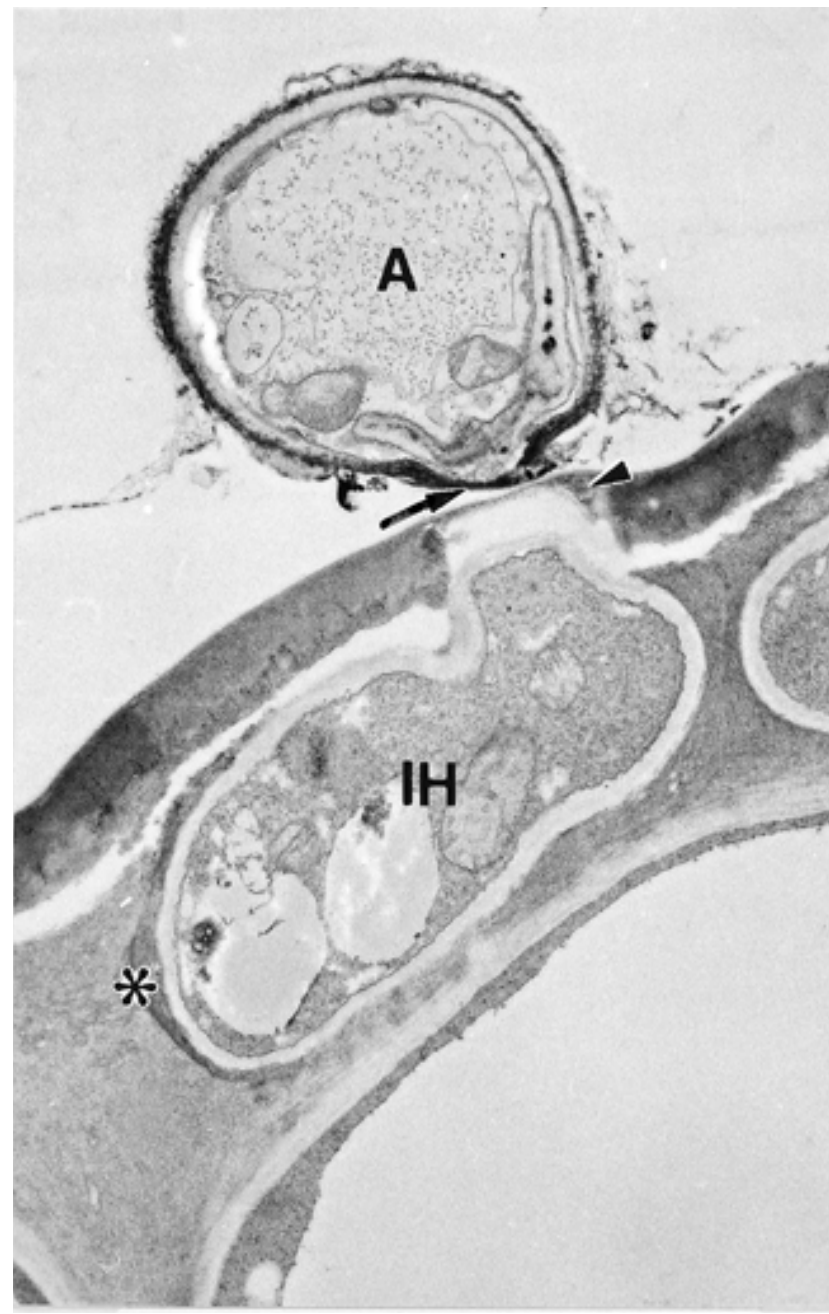

Fig. 6. Appressorium (A) with infection hyphae (IH) located in the pectin layers of nonhost European pear (cv. Flemish Beauty) leaf 2 days after inoculation. Three types of densely stained materials can be seen at the appressorium-epidermis encounter site. The arrow indicates densely stained materials between the appressorium and cuticle layers, the arrowhead indicates stained materials in cuticle layers, and the asterisk indicates those in pectin layers as indicated in Figures 3 and 5. Magnification $\times 10,000$. sac. The walls of infection pegs (Fig. 5, double arrowhead) emerged from the walls of infection sacs and the pegs penetrated the cuticles of pear leaves 1 day after inoculation (Fig. 5). At the appressorium-epidermis encounter sites, three similar types of densely stained materials also were identified, as observed on susceptible pear leaves. They were observed in the spaces between appressorial bottom and the cuticles (Figs. 5 and 6, arrows), in cuticle layers in contact with the infection pegs (Figs. 5 and 6, arrowheads), and in the pectin layers in contact with the infection hyphae (Figs. 5 and 6, asterisks). After fungal penetration through cuticles, the subcuticular hyphae continued to grow along the pectin layers within 3 days after inoculation. Some collapsed subcuticular hyphae were found in resistant and nonhost pear leaves 3 days after inoculation (Figs. 7 to 9).

Localization of subcuticular hyphae of $V$. nashicola in pear leaves. After formation of the subcuticular stroma, hyphae were found only in the pectin layers, especially in pectin-containing

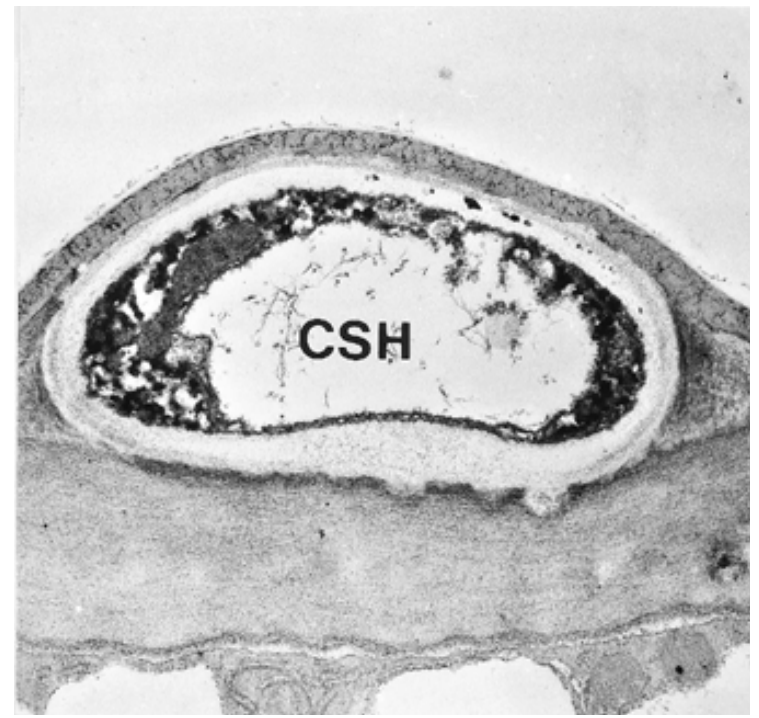

Fig. 8. Collapsed subcuticular hyphae (CSH) showing plasmolyzed, coagulated cytoplasm and attenuated cell walls in resistant Japanese pear (cv. Kinchaku) leaf 7 days after inoculation. No organelles could be recognized due to electron-dense and granulated cytoplasm. Magnification $\times 15,000$.

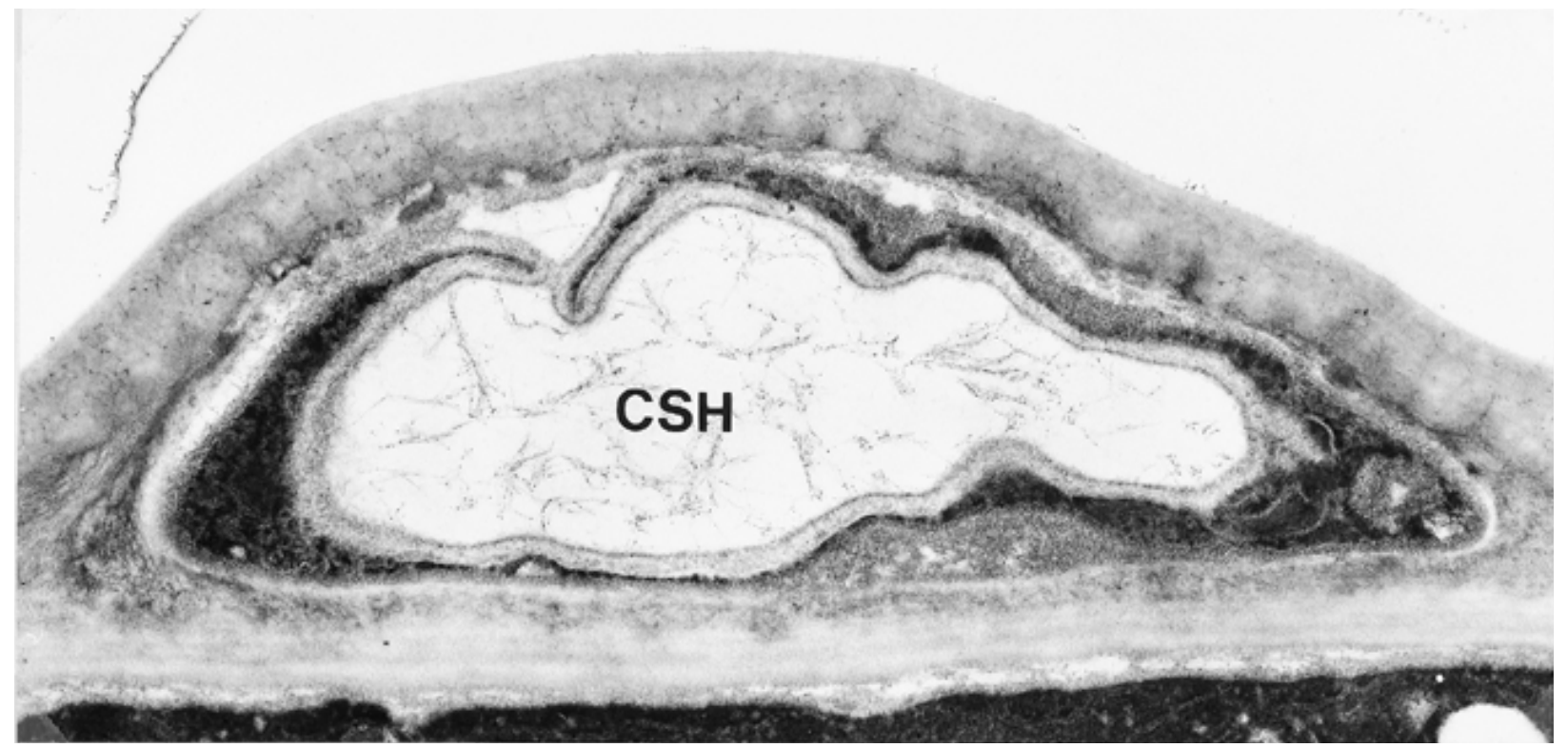

Fig. 7. Collapsed subcuticular hyphae (CSH) showing deformed cell walls subsided towards cytoplasm and necrotic cytoplasm in resistant Japanese pear (cv. Kinchaku) leaf 3 days after inoculation. Fibrous materials can be observed in the space between the subsided cell walls and host pectin layers. Magnification $\times 22,000$. 
junctures between the epidermal cells (Tables 1 and 2). The number of juncture-located subcuticular hyphae increased in both susceptible and resistant pear leaves with the time after inoculation. However, the frequency of hyphae in junctures was higher in susceptible pear leaves than in resistant and nonhost leaves. Subcuticular hyphae did not invade the epidermal cells in the pear plants 7 days after inoculation (Table 2).

Collapsed subcuticular hyphae of $V$. nashicola in pear leaves. No ultrastructural changes were observed in subcuticular hyphae in susceptible pear leaves $0.5,1,2,3,5$, and 7 days after inoculation. However, some of the hyphae were modified in both resistant Japanese pear and nonhost European pear leaves begin-

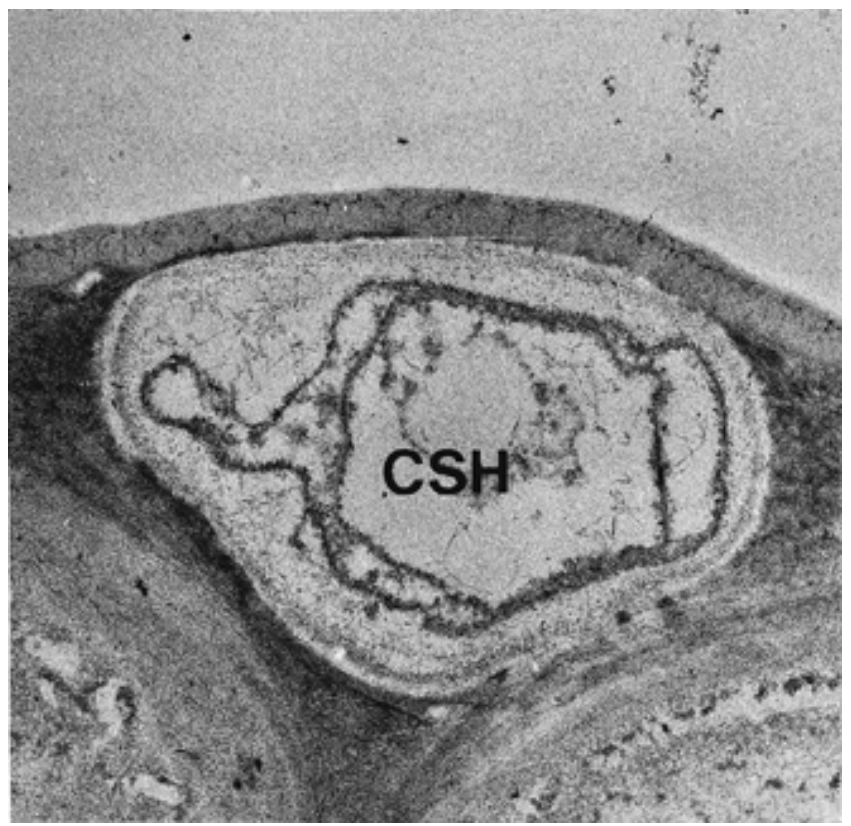

Fig. 9. Collapsed subcuticular hyphae (CSH) showing the degraded cytoplasm in nonhost European pear (cv. Flemish Beauty) leaf 5 days after inoculation. Magnification $\times 20,000$.

TABLE 1. Comparative frequency of junctures which contained subcuticular hyphae between the upper epidermis in susceptible, resistant, and nonhost pear leaves inoculated with Venturia nashicola

\begin{tabular}{|c|c|c|c|c|}
\hline Pear plants ${ }^{\mathrm{a}}$ & $\begin{array}{l}\text { Time } \\
\text { (days) }^{\mathrm{b}}\end{array}$ & Junctures $^{c}$ & $\begin{array}{c}\text { Junctures } \\
\text { with hyphae }\end{array}$ & $\begin{array}{c}\text { Frequency } \\
(\%)\end{array}$ \\
\hline \multirow[t]{6}{*}{ Susceptible } & 0.5 & 266 & 25 & 9.4 \\
\hline & 1 & 57 & 10 & 17.5 \\
\hline & 2 & 341 & 85 & 24.9 \\
\hline & 3 & 275 & 92 & 33.5 \\
\hline & 5 & 96 & 25 & 26.0 \\
\hline & 7 & 376 & 122 & 32.4 \\
\hline \multirow[t]{6}{*}{ Resistant } & 0.5 & 352 & 13 & 3.7 \\
\hline & 1 & 362 & 24 & 6.5 \\
\hline & 2 & 230 & 32 & 13.9 \\
\hline & 3 & 174 & 19 & 10.9 \\
\hline & 5 & 457 & 27 & 5.9 \\
\hline & 7 & 653 & 34 & 5.2 \\
\hline \multirow{5}{*}{ Nonhost } & 1 & 432 & 4 & 0.9 \\
\hline & 2 & 223 & 13 & 5.8 \\
\hline & 3 & 120 & 17 & 14.2 \\
\hline & 5 & 176 & 17 & 9.7 \\
\hline & 7 & 193 & 47 & 24.4 \\
\hline
\end{tabular}

${ }^{\mathrm{a}}$ Susceptible $=\mathrm{cv}$. Kosui, Resistant $=\mathrm{cv}$. Kinchaku, and nonhost $=\mathrm{cv}$. Flemish Beauty.

$\mathrm{b}$ Inoculation time.

${ }^{\mathrm{c}}$ Number of junctures between epidermis observed. The junctures indicated the triangular-shaped pectin layers beneath cuticle layers and were located between upper epidermal cells of the pear leaves.

${ }^{d}$ Number of junctures between epidermis observed which contained subcuticular hyphae. ning 3 days after inoculation (Table 3). Cytoplasm of the hyphae coagulated and highly electron-dense cytoplasm and plasmolysis occurred in resistant leaves 3 days after inoculation (Fig. 7). The cell walls of necrotic fungal cell appeared decomposed and attenuated. In resistant leaves, some fungal cell walls subsided inside the cytoplasm of hyphae 3 days after inoculation (Fig. 7). The fungal cells appeared necrotic. Fibrilar materials were usually observed in the spaces between fungal cell walls and pectin layers of resistant pear leaves 7 days after inoculation (Fig. 8). Eventually, most hyphae collapsed and general disruption of cellular membranes was observed. Empty cytoplasm was often seen in the collapsed hyphae. The ultrastructural modifications seen in resistant leaves were also found in nonhost pear leaves (Fig. 9); there were no obvious differences between these pear leaves (Figs. 7 to 9).

\section{DISCUSSION}

Yamamoto and Tanaka (26) first reported that $V$. nashicola penetrated leaves of the scab-susceptible Japanese pear cv. Chojuro through the cuticle. Therefore, it has been thought that cutinase activity of $V$. nashicola plays an important role in the

TABLE 2. Localization of subcuticular hyphae in cell walls of susceptible, resistant, and nonhost pear leaves inoculated with Venturia nashicola

\begin{tabular}{lccccc}
\hline & \multirow{2}{*}{$\begin{array}{c}\text { Time } \\
\text { Pear plants }\end{array}$} & \multicolumn{4}{c}{ Number of subcuticular hyphae } \\
\cline { 3 - 6 } & ${\text { (days })^{\mathrm{b}}}^{\mathrm{n}}$ & Observed & In pectin & In cellulose & In epidermal cells \\
\hline Susceptible & 0.5 & 95 & 95 & 0 & 0 \\
& 1 & 24 & 24 & 0 & 0 \\
& 2 & 64 & 64 & 0 & 0 \\
& 3 & 45 & 45 & 0 & 0 \\
& 5 & 14 & 14 & 0 & 0 \\
Resistant & 7 & 7 & 7 & 0 & 0 \\
& 0.5 & 17 & 17 & 0 & 0 \\
& 1 & 9 & 9 & 0 & 0 \\
& 2 & 3 & 3 & 0 & 0 \\
Nonhost & 3 & 45 & 45 & 0 & 0 \\
& 5 & 23 & 23 & 0 & 0 \\
& 7 & 37 & 37 & 0 & 0 \\
& 2 & 19 & 19 & 0 & 0 \\
& 3 & 10 & 10 & 0 & 0 \\
& 5 & 8 & 12 & 0 & 0 \\
& 7 & 40 & 4 & 0 & 0 \\
& 5 & 40 & 0 & 0
\end{tabular}

${ }^{\mathrm{a}}$ Susceptible $=\mathrm{cv}$. Kosui, Resistant $=\mathrm{cv}$. Kinchaku, and nonhost $=\mathrm{cv}$. Flemish Beauty.

${ }^{\mathrm{b}}$ Inoculation time.

TABLE 3. Comparative frequency of collapsed subcuticular hyphae in cell walls of susceptible, resistant, and nonhost pear leaves inoculated with Venturia nashicola

\begin{tabular}{lcccc}
\hline Pear plants $^{\mathrm{a}}$ & Time (days) $^{\mathrm{b}}$ & Hyphae $^{\mathrm{c}}$ & Collapsed $^{\mathrm{d}}$ & Frequency $(\%)^{\text {Susceptible }}$ \\
\hline & 0.5 & 50 & 0 & 0 \\
& 3 & 42 & 0 & 0 \\
\multirow{3}{*}{ Resistant } & 5 & 121 & 2 & 1.7 \\
& 7 & 28 & 1 & 3.6 \\
& 0.5 & 35 & 0 & 0 \\
& 1 & 42 & 0 & 0 \\
& 2 & 69 & 0 & 0 \\
\multirow{3}{*}{ Nonhost } & 3 & 41 & 10 & 24.4 \\
& 5 & 109 & 13 & 11.9 \\
& 7 & 106 & 26 & 24.5 \\
& 2 & 29 & 0 & 0 \\
& 3 & 64 & 7 & 10.9 \\
& 5 & 30 & 30 & 100 \\
& 7 & 90 & 62 & 68.9
\end{tabular}

${ }^{\mathrm{a}}$ Susceptible $=\mathrm{cv}$. Kosui, Resistant $=\mathrm{cv}$. Kinchaku, and nonhost $=\mathrm{cv}$. Flemish Beauty.

${ }^{b}$ Inoculation time.

c Number of subcuticular hyphae observed.

${ }^{d}$ Number of collapsed subcuticular hyphae. 
pathogenesis of scab during the penetration process (16). However, our results suggest that cutinase activity is not associated with species- or cultivar-specific scab resistance in pears because we found that $V$. nashicola penetrated the cuticle of all susceptible, resistant, and nonhost pear plants used. In addition, no differences were observed in conidial germination, germ tube growth, and the formation of appressoria, penetration pores, and subcuticular hyphae, at the early stages of infection, regardless of the pear cultivars used. This suggests that resistance to scab expressed after penetration of the cuticle by the fungus. Similar results were obtained in earlier studies of the infection behavior of $V$. inaequalis in apple leaves (17). Our studies and a study on $V$. inaequalis-infected apple (25) indicate that the cuticle layers do not represent an effective physical barrier for these pathogens.

In our ultrastructural study, we observed slime substances involving germ tubes and appressoria on leaf surfaces before the formation of infection hyphae from the appressoria. Germ tubes and appressoria were covered with slime substances, but the conidia were uncovered. The substances consisted of fibrous network materials and dense granular components. Adachi et al. (1) showed that these substances appeared to be secreted from germ tubes and appressoria but not from conidia. The fibrous materials of slime were positively stained with alkaline bismuth solution for polysaccharides (18), indicating that it had polysaccharide components. Slime substances have also been reported in germinated ascospores of $V$. inaequalis on apple leaf surfaces (22). These substances appear to be involved in the adhesion of germ tubes and appressoria.

No ultrastructural differences were observed in the early stages of infection of $V$. nashicola, within 3 days after inoculation, regardless of pear cultivars used. Hyphae proliferated horizontally in the pectin layers between the cuticle and cellulose layers and then became subcuticular hyphae or stroma. The subcuticular hyphae were always localized in pectin layers, especially in pectincontaining junctures between epidermal cells (Table 1), but never in epidermal cytoplasm (Table 2). Our results showed that $V$. nashicola was an inhabitant of pectin layers, suggesting that the subcuticular hyphae produce pectinase as well as cutinase from infection hyphae or subcuticular hyphae.

Three similar types of densely stained materials were found at $V$. nashicola-epidermal cell encounter sites in susceptible, resistant, and nonhost pear leaves inoculated with the fungus. The first was observed in waxes between the base of the appressoria and the cuticle layers. The second was localized in cuticle layers in the vicinity of the infection hyphae, and the third was restricted to pectin layers near the infection hyphae or subcuticular hyphae. It is unclear what these densely stained materials at the encounter sites are composed of. There are three possible explanations for the formation of the materials. The materials may be a result of the enzymatic degradation products from waxes, cuticles, pectin, and cellulose exposed to cell wall-degrading fungal enzymes (3). The second possibility is that the materials are the enzymes themselves involved in or near cell walls of fungus-infected plants. Glutaraldehyde, used for electron microscopy, preserves proteins such as fungal enzymes at the primary fixation of biological materials well, but does not preserve lipids (6). On the contrary, subsequent fixation with osmium tetroxide can preserve unsaturated fatty acids of lipids or biological membranes well, but does not preserve proteins (6). Double fixation using glutaraldehyde and osmium tetroxide and the electron stains using uranyl acetate and lead citrate usually allow us to observe less stained or electronlucent images of cell walls because polysaccharides, the main components of cell walls, almost never react with fixatives and stains $(6,7)$. The free carboxyl groups of fungal enzymes which had been well preserved with glutaraldehyde might be positively reactive with acidic uranyl acetate. In addition, the free carboxyl, sulphhydryl, and tyrosil groups of proteins reacted well with alkaline lead solution. Therefore, taking account of the chemical reac- tions of the fixatives and stains to biological components, it is likely that fungal enzymes from infection hyphae or subcuticular hyphae can be captured as visualized images at fungus-epidermis encounter sites by the conventional double fixation method and the electron stains. The third possibility is that there is a mixture of both degraded products and fungal enzymes captured at the encounter sites.

Cell death of subcuticular hyphae was observed only in resistant and nonhost pear leaves 3 days after inoculation. The modified hyphae had destroyed plasma membranes, shriveled and coagulated cytoplasm with degraded organelles, necrotic cytoplasm, empty cytoplasm sometimes, and attenuated cell walls, indicating the death of fungal cells ultrastructurally. The modified hyphae increased in number beginning 3 days after inoculation (Table 3). V. nashicola inhabits pectin layers; therefore, we expected it to produce some types of pectinases, which may play an important role in absorbing nutrients from pear plants. Recently, polygaracturonases produced by $V$. nashicola and $V$. pirina were purified and characterized (11). If the pectinase activity of $V$. nashicola is inhibited by any substances from pear leaves, for example, by polygaracturonase inhibiting proteins (PGIP) which have been found in beans (24) and $V$. inaequalis-infected resistant apple plants (12), the fungus would die during proliferation in the leaves. Thus, fungal cell death may be attributed to the production of PGIP by $V$. nashicola-infected resistant and nonhost pear leaves. Other mechanisms, including the accumulation of fungitoxic phenolic compounds, might also be involved in scab resistance.

\section{ACKNOWLEDGMENTS}

We thank K. Kotobuki, National Institute of Fruit Tree Science, and M. Fukaya, Tenno Branch, Akita Fruit Tree Experimental Station, for providing pear scions.

\section{LITERATURE CITED}

1. Adachi, Y., Park. P., Kanematsu, S., Ishii, H., and Ieki, H. 1997. Electron microscopical observation of the mucilaginous substance secreted from conidia of Venturia nashicola, causal agent of scab of Japanese pear. J. Tech. Res. Conf. Med. Biol. Electron Microsco. 12:83.

2. Aderhold, R. 1896. Die Fusicladien unserer Obstbäume. I. Teil. Landwirtsch. Jahb. 25:875-914.

3. Becker, C. M. 1993. The cytology and histology of apple scab. Pages 3590 in: Handbook of Cytology, Histology, and Histochemistry of Fruit Tree Diseases. A. R. Biggs, ed. CRC Press, Boca Raton, FL.

4. Corlett, M., and Chong, J. 1977. Ultrastructure of the appressorium of Spilocaea pomi. Can. J. Bot. 55:5-7.

5. Granett, A. L. 1974. Ultrastructural studies of concentric bodies in the ascomycetous fungus Venturia inaequalis. Can. J. Bot. 52:2137-2139.

6. Hayat, M. A. 1989. Chemical fixation. Pages 1-78 in: Principles and Techniques of Electron Microscopy, 3rd ed. MacMillan Press, London.

7. Hayat, M. A. 1989. Positive staining. Pages 208-327 in: Principles and Techniques of Electron Microscopy, 3rd ed. MacMillan Press, London.

8. Ishii, H., Udagawa, H., Nishimoto, S., Tsuda, T., and Nakashima, H. 1992. Scab resistance in pear species and cultivars. Acta Phytopathol. Entomol. Hung. 27:293-298.

9. Ishii, H., Watanabe, H., and Tanabe, K. 1997. Physiological races of Venturia nashicola on pears. IOBC/WPRS Bull. 20:130-133.

10. Ishii, H., and Yanase, H. 2000. Venturia nashicola, the scab fungus of Japanese and Chinese pears: a species distinct from V. pirina. Mycol. Res. 104:755-759.

11. Isshiki, A., Akimitsu, K., Ishii, H., and Yamamoto, H. 2000. Purification of polygalacturonases produced by the pear scab pathogens, Venturia nashicola and V. pirina. Physiol. Mol. Plant Pathol. 56:263-271.

12. Komianc, M., Schmid, S., Cervone, F., and De Lorenzo, G. 1996. Accumulation of PGIP like mRNA in apple induced by Venturia inaequalis and salicylic acid treatment. Abstr. 4th Workshop Integrated Control Pome Fruit Dis. 38-40.

13. MacHardy, W. E. 1996. Apple Scab: Biology, epidemiology, and management. The American Phytopathological Society, St. Paul, MN.

14. Maeda, K. M. 1970. An ultrastructural study of Venturia inaequalis (Cke.) Wint. infection of Malus hosts. MS thesis, Purdue University, Lafayette, IN.

15. Mims, C. W. 1991. Using electron microscopy to study plant pathogenic 
fungi. Mycologia 83:1-19.

16. Müller, M. W., and Ishii, H. 1997. Esterase activity from Venturia nashicola: histochemical detection and supposed involvement in the pathogenesis of scab on Japanese pear. J. Phytopathol. 145:473-477.

17. Nicholson, R. L., Van Scoyoc, S., Williams, E. B., and Kuć, J. 1977. Host-pathogen interactions preceding the hypersensitive reaction of Malus sp. to Venturia inaequalis. Phytopathology 67:108-114.

18. Park, P., Ohno, T., Kato-Kikuchi, H., and Miki, H. 1987. Alkaline bismuth stain as a tracer for Golgi vesicles of plant cells. Stain Technol. 62:253-256.

19. Park, P., and Unno, K. 1999. Temporary acceleration of exocytosis of polysaccharides in susceptible strawberry leaves by AF-toxin I from $\mathrm{Al}$ ternaria alternata strawberry pathotype. Ann. Phytopathol. Soc. Jpn. 65: 515-520.

20. Reynolds, E. S. 1963. The use of lead citrate at high $\mathrm{pH}$ as an electron opaque stain in electron microscopy. J. Cell Biol. 17:208-212.

21. Sato, T. 1967. A modified method for lead staining of thin sections. J.
Electron Microsc. 16:133.

22. Smereka, K. J., Kausch, A. P., and MacHardy, W. E. 1988. Intracellular junctional structures in germinating ascospores of Venturia inaequalis. Protoplasma 142:1-4.

23. Tanaka, S., and Yamamoto, S. 1964. Studies on pear scab. II. Taxonomy of the causal fungus of Japanese pear scab. Ann. Phytopathol. Soc. Jpn. 29:128-136

24. Toubart, P., Desiderio, A., Salvi, G., Cervone, F., Daroda, L., and De Lorenzo, G. 1992. Cloning and characterization of the gene encoding the endopolygaracturonase-inhibiting protein (PGIP) of Phaseolus vulgaris L. Plant J. 2:367-373.

25. Valsangiacomo, C., and Gessler, C. 1988. Role of the cuticular membrane in ontogenic and Vf-resistance of apple leaves against Venturia inaequalis. Phytopathology 78:1066-1069.

26. Yamamoto, S., and Tanaka, S. 1963. Studies on pear scab (Venturia spp.) III. Infection on the leaves by conidia. Bull. Hortic. Res. Stn. Jpn. B: 181-192. 